Tersedia online di

\title{
Evaluasi Kapasitas Saluran Drainase Pada Catchment Area Sub Sistem Bendul Merisi Kota Surabaya
}

\author{
D. A. D. Nusantara*1

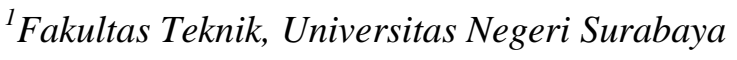 \\ email :*1 danayantinusantara@unesa.ac.id
}

\begin{tabular}{ll} 
A R T I C L E & I N F O \\
\hline Article history : & \\
Artikel masuk & $: 26-02-2020$ \\
Artikel revisi & $: 30-03-2020$ \\
Artikel diterima & $: 31-03-2020$ \\
\hline
\end{tabular}

Keywords :

Drainage Channel, Flood Discharge, Channel Capacity, Channel Planning.

Style IEEE dalam mensitasi artikel ini : [1]

K. Sari, "Management strategy of sustainable urban drainage in Pekanbaru City," IOP Conf. Ser. Earth Environ. Sci., vol. 361, no. 1, 2019.

\begin{abstract}
A B S TR A C T
Bendul Merisi is a densely populated urban village located in the city of Surabaya with a population density, which until 2014 reached 12,477 inhabitants. The drainage channel in Bendul Merisi is unable to collect rainwater, causing water overflow in the drainage canal. The way to overcome flood is to increase the capacity of the channel. Evaluation of drainage channel capacity in Bendul Merisi is needed for flood management. The purpose of this study is to find out the amount of capacity of the drainage channel, so flood can be overcome, can find out the results of the evaluation of flood volume for the next 2 years with the existing channel capacity. The results of this study are the dimensions of the tertiary channel 2 using a width of $1.9 \mathrm{~m}$ and a depth of 2.1 $m$; quarterly channel 1 uses a width of $0.6 \mathrm{~m}$ and a depth of $1.5 \mathrm{~m}$; Q2 channel uses $a$ width of $2 \mathrm{~m}$ and a depth of 2.98 $m$. The expansion of the cross-section is expected to be overcome.
\end{abstract}

\section{A B S T R A K}

Bendul Merisi merupakan kelurahan padat penduduk yang terletak di Kota Surabaya dengan kepadatan penduduk yang sampai pada tahun 2014 mencapai 12.477 jiwa. Saluran pembuang di Bendul Merisi tidak mampu menampung air hujan sehingga mengakibatkan meluapnya air di saluran pembuang banjir. Cara penanggulangan banjir adalah memperbesar kapasitas saluran. Evaluasi kapasitas saluran drainase di Bendul Merisi diperlukan, untuk penanganan banjir. Tujuan dari penelitian ini dapat mengetahui jumlah kapasitas tampungan saluran drainase, sehingga bajir dapat teratasi, dapat mengetahui hasil evaluasi volume banjir untuk 2 tahun yang mendatang dengan kapasitas saluran yang ada. Hasil penelitian ini adalah dimensi saluran tersier 2 menggunakan lebar $1,9 \mathrm{~m}$ dan kedalaman 2,1 m; saluran kuarter 1 menggunakan lebar 0,6 m dan kedalaman 1,5 m; saluran kuarter 2 menggunakan lebar $2 \mathrm{~m}$ dan kedalaman $2,98 \mathrm{~m}$. Pembesaran penampang diharapkan banjir dapat teratasi. 


\section{Pendahuluan}

Bendul Merisi merupakan kelurahan padat penduduk yang terletak di Kota Surabaya dengan kepadatan penduduk yang sampai pada tahun 2014 mencapai 12.477 jiwa dan semakin hari terus bertambah pesat, akibatnya saluran pembuangan yang dulunya lebar dan dalam menjadi sempit dan dangkal, perubahan ini telah membuat daya fungsi penyerapan menjadi rendah [1][2]. Seiring semakin banyaknya pemukiman yang berkembang baik untuk tempat tinggal maupun untuk usaha akibatnya kapasitas tampungan air berkurang [3][4][5]. Dan bila musim penghujan datang, kapasitas saluran pembuang di Bendul Merisi - Surabaya tidak mampu menampung air hujan sehingga mengakibatkan meluapnya air di saluran pembuang dan banjir (BPS Kota Surabaya) [6][7][8]. Permasalahan banjir dan genangan di Indonesia merupakan masalah nasional yang mempengaruhi seluruh aspek kehidupan masyarakat [9][10].

Sistem drainase merupakan salah satu komponen infrastruktur yang sangat penting [11]. Sistem drainase yang baik dan berkelanjutan menjadi kebutuhan suatu daerah serta harus memastikan pembuangan air permukaan yang aman tanpa membahayakan bangunan, keselamatan manusia dan lingkungan [12][13][14]. Kata drainase berasal dari kata drainage yang artinya mengeringkan atau mengalirkan [15], dalam bidang teknik sipil drainase secara umum dapat didefinisikan sebagai serangkaian bangunan air yang berfungsi untuk mengurangi kelebihan air, baik yang berasal dari air hujan, rembesan, maupun kelebihan air irigasi dari suatu kawasan atau lahan [16]. Contoh dari bangunan drainase yaitu goronggorong, pertemuan saluran, terjunan, jembatan, tali-tali air, pompa, dan pintu air [17][18].

Pemerintah Kota Surabaya sudah berupaya keras untuk menanggulangi banjir dengan cara memperbesar saluran pembuang tapi tidak membuat jalan sempit, yaitu dengan pemasangan box culvert dengan kapasitas sesuai dengan jumlah air yang meluapagar banjir segera teratasi, oleh sebab itu perlu adanya evaluasi kapasitas saluran drainase di Bendul Merisi Kota Surabaya dengan kemiringan lahan 0.0001. Pada saat terjadi banjir daerah Bendul Merisi terendam air sedalam $20 \mathrm{~cm}$ atau diatas mata kaki orang dewasa dengan lama genangan 2 jam. Lokasi penelitian di Kelurahan Bendul Merisi yang secara administrasi terdiri 83.735 jiwa terdiri dari12 RW dan 58 RT dengan luas wilayah $0.77 \mathrm{Km} 2$.

Tujuan dari penelitian ini dapat mengetahui jumlah kapasitas tampungan saluran drainase, sehingga bajir dapat teratasi, dapat mengetahui hasil evaluasi volume banjir untuk 2 tahun yang mendatang dengan kapasitas saluran yang ada. 


\section{Tinjauan Pustaka}

\subsection{Intensitas Hujan.}

Intensitas hujan adalah tinggi air hujan persatuan waktu dengan satuan mm/jam. Besarnya intensitas air hujan yang berbeda-beda disebabkan oleh lamanya hujan atau frekuensi terjadinya hujan[19].

\subsection{Analisis Hidrologi.}

Proses analisis hidrologi merupakan proses pengolahan data curah hujan, data luas dan bentuk daerah pengaliran (Catchment Area), data kemiringan lahan/ beda tinggi, dan data tata guna lahan yang kesemuanya mempunyai arahan untuk mengetahui besarnya curah hujan rerata, koefisien pengaliran, waktu konsentrasi, intensitas curah hujan, dan debit banjir rencana. Sehingga melalui analisis ini dapat dilakukan juga proses evaluasi terhadap saluran drainase yang ada (Eksisting) [20][21][22].

\subsection{Hujan Rancangan.}

Hujan rancangan untuk perencanaan saluran drainase digunakan kala ulang 2, 5 dan 10 tahun. Kala ulang adalah waktu hipotetik di mana hujan dengan suatu besaran tertentu akan disamai atau dilampaui. Dalam hal ini tidak terkandung pengertian bahwa kejadian tersebut akan berulang secara teratur mengikuti kala ulang [6].

\subsection{Saluran Drainase.}

Saluran drainase harus direncanakan untuk dapat melewatkan debit rencana dengan aman. Perencanaan teknis saluran drainase menurut Supirin mengikuti tahapan-tahapan denan menentukan debit rencana, menentukan jalur saluran, merencanakan profil memanjang saluran, merencanakan penampang melintang saluran, mengatur dan merencanakan bangunan- bangunan serta fasilitas sistem drainase [16][23].

\subsection{Kapasitas Saluran.}

Kapasitas saluran drainase dihitung dengan menggunakan Rumus Manning dan Rumus Kontinuitas [9] :

- Rumus Manning v $=1 / \mathrm{n} \cdot \mathrm{R}^{2 / 3} \cdot \mathrm{S}^{1 / 2}$ - $\quad$ Rumus Kontinuitas Q = A .v

Dengan :

$\mathrm{V}=$ Kecepatan aliran rata-rata saluran $(\mathrm{m} / \mathrm{dt}) . \quad \mathrm{A}=$ luas penampang basah $(\mathrm{m} 2)$.

$\mathrm{R}=$ jari - jari hidrolis $(\mathrm{m}) . \quad \mathrm{P}=$ keliling basah saluran $(\mathrm{m})$.

$\mathrm{Q}=\operatorname{debit}(\mathrm{m} 3 / \mathrm{dt}) . \quad \mathrm{n}=$ koefisien kekasaran manning. 


\subsection{Evaluasi dan Perencanaan Ulang Saluran Drainase.}

Evaluasi sistem jaringan drainase yang ada digunakan untuk mengetahui saluransaluran yang tidak mampu menampung debit air hujan dengan intensitas tertentu dan limbah domestik sebagai penyebab terjadinya genangan. Jika Qranc > Qkap maka saluran perlu untuk direncanakan ulang, sedangkan jika Qranc < Qkap maka tidak perlu dilakukan perencanaan ulang [24].

\subsection{Faktor yang Mempengaruhi Daya Tampung Sistem Drainase.}

Faktor-faktor yang mempengaruhi daya tampung dan menyebabkan sistem drainase menjadi bermasalah telah dijelaskan dalam berkas pedoman atau standar Kementerian Pekerjan Umum SNI : 02-2406-1991 tentang Tata Cara Perencanaan Umum Drainase Perkotaan :

1. Peningkatan debit.

2. Sampah.

3. Sedimentasi.

4. Penyempitan dan pendangkalan saluran.

5. Pasang surut.

6. Reklamasi.

7. Peningkatan jumlah penduduk.

\section{Metode Penelitian}

Metode penelitian menggambarkan tahapan dari penelitian yang akan dilakukan, meliputi cara mengumpulkan data, perhitungan dan analisis untuk menjawab permasalahan yang ditanyakan dalam pertanyaan penelitian. Dalam penelitian ini metode yang dilakukan adalah metode pengumpulan data baik data sekunder maupun primer, metode analisis data hidrologi dan hidrolika. Metode interpretasi citra penginderaan jauh dilakukan. Metode pengumpulan data dilakukan untuk mengetahui untuk mengetahui informasi jenis penggunaan lahan aktual, identifikasi kondisi hidrologi, morfologi lereng dan dimensi penampang saluran drainase. Metode analisis data hidrologi untuk mengetahui debit aliran limpasan yang telah terkoreksi dan analisis data hidrolika khususnya analisis saluran terbuka untuk mengidentifikasi dimensi penampang saluran, kondisi saluran serta kapasitas saluran. Penelitian dilakukan dengan langkah - langkah untuk dapat mendiskripsikan tujuan dari penelitian, tahapan penelitian yang akan dilakukan meliputi tahap pengumpulan data, analisa data dan perumusan hasil analisa. 


\subsection{Tahapan Penelitian.}

Penulis melakukan survey lapangan agar mengetahui secara pasti kondisi saluran drainase yang ada di Kelurahan Bendul Merisi Kota Surabaya, survey dilakukan pada saat kondisi hujan agar bisa mengetahui kondisi realnya. kondisi real saluran drainase Kelurahan Bendul Merisi Kota Surabaya, termasuk kondisi pada saat ada genangan.

Gambar rencana dimensi saluran termasuk juga penampang melintang dan penampang memanjang sungai, data tersebut diperoleh dari Dinas Pematusan dan Cipta Karya Pemerintah Kota Surabaya. Data curah hujan disekitar Kelurahan Bendul Merisi Kota Surabaya sebanyak 10 tahun, data tersebut diperoleh dari UPT. PSDA di Surabaya Dinas PU. Sumberdaya Air Prov. Jawa Timur. Data daerah tangkapan, topografi termasuk juga peta wilayah, data tersebut diperoleh dari Dinas Pematusan dan Cipta Karya Pemerintah Kota Surabaya.

Setelah semua data - data sekunder dan primer diolah, maka langkah selanjutnya menganalisis, baik itu analisis hidrologi maupun analisis hidrolika, namun sebelumnya perlu dilakukan analisa data untuk memperbandingkan tingkat keakuratan data yang terhimpun. Dalam penelitian ini dilakukan 2 (dua) jenis analisa yaitu analisa hidrologi yang pada akhirnya akan menghasilkan debit rancangan hujan dan analisa hidrolika yang hasil akhirnya berupa kapasitas dan debit saluran eksisting. Pembahasan akhir dari kedua analisa adalah saling berhubungan apakah debit rancangan hujan dapat tertampung dalam saluran air hujan sesuai dengan kapasitas terpasangnya atau kapasitas eksistingnya.

Data hujan yang ada didapatkan dihitung Intensitas curah hujan dan Frekuensinya. Data - data yang telah diolah selanjutnya di analisa secara berurutan dimulai dari analisa frekuensi hujan, untuk menentukan model distribusi perhitungan curah hujan dengan periode ulang yang tepat dengan 3 factor koefisien variansi, koefisien skewness dan koefisien kurtois. Perhitungan probabilitasnya menggunakan uji smirnov-kolgomorov dan uji chi-square.

Intensitas hujan terpilih adalah intensitas hasil analisis frekuensi dan hasil pengujian probabilitas uji smirnov-kolgomorov dan uji chi-square untuk menghasilkan lengkung Intensitas-Durasi-Frekuensi. Data pencatatan hujan merupakan data otomatis, maka analisis intensitas hujan didasarkan pada kurva lengkung Intensitas-Durasi-Frekuensi yang dihasilkan dari tabulasi data hujan otomatis. jika data pencatatan hujan merupakan data harian, maka metode analisis intensitas hujan dapat dilakukan dengan menggunakan metode Talbot, Sherman, Mononobe dan Ishiguro. Pemilihan lengkung terbaik diantara metode - metode tersebut dilihat dari deviasi kecil antara data terukur dan hasil prediksi. 
Data penggunaan lahan dan data topografi menghasilkan analisa perhitungan antara luasan dengan koefisien aliran permukaan. Bentuk topografi, jenis penggunaan lahan dan jenis tanah sangat mempengaruhi nilai dari koefisien aliran permukaan. Dengan menggunakan pendekatan rasional, debit rancangan hujan dapat diperkirakan dan selanjutnya dapat diperhitungkan waktu pengaliran air hujan atau limpasan hujan yang jatuh untuk mengalir dari titik terjauh sampai ke tempat keluaran daerah aliran sungai 4 titik outlet. Debit rancangan hujan dan waktu konsentrasi ini menjadi unsur masukan dalam analisa hidrolika saluran terbuka yang secara eksisting telah terbangun di lokasi penelitian.

Dalam penelitian ini, analisa di titik beratkan / dikonsentrasikan pada kapasitas saluran dan sangat berhubungan erat dengan factor-factor sifat, bentuk penampang, dan kecepatan pada saluran terbuka. Sifat saluran yang diperkirakan berupa aliran tunak/mantap/permanen oleh karena sebagian besar saluran buatan yang terbuka mempunyai waktu aliran yang konstan dan oleh karena bentuk penampang melintangnya tetap dari hulu sampai ke hilir, maka diperkirakan sifat aliran seragam. Bentuk aliran diperkirakan berupa aliran laminair oleh karena jarang terjadi bentuk aliran turbulen pada saluran tertutup.

Data penampang saluran tertutup pada lokasi penelitian di perhitungkan sesuai dengan bentuk dan dimensi penampang melintang. Perhitungan yang dilakukan adalah memperhitungkan kapasitas debit berdasarkan kecepatan aliran dan luas penampang basah. Setelah itu dilakukanlah analisis data. Hasil dari penelitian dapat ditarik kesimpulan.

\subsection{Lokasi Penelitian.}

Lokasi pelaksanaan penelitian berikut dilakukan pada Kelurahan Bendul Merisi Kota Surabaya.

\section{Hasil dan Pembahasan}

Dari hasil survey digunakan data pengamatan terhadap 3 stasiun yaitu stasiun Wonorejo, stasiun Wonokromo, dan stisiun Gunungsari. Dari ketiga stasiun tersebut didapatkan data cathment area Stasiun Wonokromo $5 \mathrm{Km}$, Stasiun Wonorejo $5 \mathrm{Km}$, Stasiun Gunungsari $5 \mathrm{Km}$. Selengkapnya dapat dilihat pada Tabel 1. 
Tabel 1. Data Pengamatan Hujan

\begin{tabular}{ccccc}
\hline No & Tahun & $\begin{array}{c}\text { Stasiun } \\
\text { Wonorejo }\end{array}$ & $\begin{array}{c}\text { Stasiun } \\
\text { Wonokromo }\end{array}$ & $\begin{array}{c}\text { Stasiun } \\
\text { Gunungsari }\end{array}$ \\
\hline 1 & 2009 & 98 & 104 & 78 \\
2 & 2010 & 98 & 110 & 114 \\
3 & 2011 & 94 & 98 & 102 \\
4 & 2012 & 95 & 106 & 102 \\
5 & 2013 & 85 & 87 & 97 \\
6 & 2014 & 100 & 83 & 86 \\
7 & 2015 & 109 & 63 & 70 \\
8 & 2016 & 121 & 108 & 94 \\
9 & 2017 & 122 & 114 & 120 \\
10 & 2018 & 85 & 73 & 85 \\
\hline
\end{tabular}

Sumber: Pengamatan Hujan.

Berikut hasil perthitungan data saluran eksisting menjelaskan dampak yang terjadi akibat dimensi saluran yang menyempit adalah tidak tertampungnya air buangan warga, apalagi ditambah dengan debit yang berasal dari air hujan membebani saluran eksisting. Selengkapnya dapat dilihat pada Tabel 2.

Tabel 2. Perhitungan Data Eksisting.

\begin{tabular}{ccccccc}
\hline $\begin{array}{c}\text { Bentuk } \\
\text { Penampang }\end{array}$ & $\begin{array}{c}\text { Keliling } \\
\text { Basah }(\mathbf{P})\end{array}$ & $\mathbf{n}$ & $\begin{array}{c}\text { Jari-jari } \\
\text { Hidrolis }(\mathbf{R})\end{array}$ & $\begin{array}{c}\text { Kemiringan } \\
\text { Dasar Saluran } \\
(\mathbf{S})\end{array}$ & $\begin{array}{c}\text { Kecepatan } \\
(\mathbf{V s})\end{array}$ & $\begin{array}{c}\text { Kapasitas } \\
\text { Saluran } \\
(\mathbf{Q})\end{array}$ \\
& $\mathbf{m}$ & & $\mathbf{m}$ & & $\mathbf{m} / \mathbf{d e t}$ & $\mathbf{m}^{\mathbf{3} / \mathbf{d e t}}$ \\
\hline Trapesium & 6,7 & 0,023 & 0,74 & 0,0004 & 0,71 & 3,51 \\
Segi Empat & 148,93 & 0,023 & 0,03 & 0,0005 & 0,09 & 0,10 \\
Segi Empat & 3,35 & 0,023 & 0,16 & 0,0004 & 0,25 & 0,13 \\
Segi Empat & 958,50 & 0,023 & 0,001 & 0,0005 & 0,01 & 0,01
\end{tabular}

\section{Sumber: Perhitungan Eksisting}

Dari hasil survey di lapangan dan pengolahan data, Bendul Merisi merupakan salah satu kelurahan yang masuk bagian dari Kecamatan Wonocolo dengan kepadatan penduduknya mencapai 86.815 jiwa dalam tahun 2017 dan mengalami peningkatan sebanyak $0.0085 \%$ per tahunnya. Selengkapnya dapat dilihat pada Tabel 3.

Tabel 3. Data Pertumbuhan Penduduk Kecamatan Wonocolo.

\begin{tabular}{ccccccr}
\hline $\begin{array}{c}\text { Nama } \\
\text { Kecamatan }\end{array}$ & $\mathbf{2 0 1 3}$ & $\mathbf{2 0 1 4}$ & $\mathbf{2 0 1 5}$ & $\mathbf{2 0 1 6}$ & $\mathbf{2 0 1 7}$ & Pertumbuhan \\
\hline Kec. Wonocolo & 83735 & 82387 & 80436 & 78337 & 86815 & 0,907149072 \\
\hline
\end{tabular}

Sumber : Data Penduduk Kecamatan Wonocolo. 
Rata-rata pertumbuhan penduduk Bendul merisi yang didapat dari Badan Pusat Statistik Surabaya dalam Angka adalah 0.0085\%. Semakin meningkatnya jumlah penduduk berdampak pada semakin berkurangnya dimensi saluran drainase yang dipergunakan untuk penduduk untuk memperluas bangunan rumahnya. Dampak yang terjadi akibat dimensi saluran yang menyempit adalah tidak tertampungnya air buangan warga, apalagi ditambah dengan debit yang berasal dari air hujan, maka akan terjadi luapan. Hitungan perkiraan debit air kotor selama 2 tahun mendatang ditampilkan pada Tabel 4.

Tabel 4. Hitungan Perkiraan Debit Air Kotor 2 Tahun.

\begin{tabular}{|c|c|c|c|c|c|}
\hline & Luas & Jumlah & Jumlah & $Q_{\text {ak total }}$ & $\mathbf{Q}_{\mathrm{ak}}$ \\
\hline Saluran & $\begin{array}{c}\text { Catchment } \\
\text { (A) } \\
\mathbf{k m}^{2}\end{array}$ & $\begin{array}{c}\text { Penduduk } \\
\text { (Po) } \\
\text { Jiwa }\end{array}$ & $\begin{array}{c}\text { Penduduk } \\
\text { (Pn) } \\
\mathbf{T}=\mathbf{2} \\
\text { tahun }\end{array}$ & $\mathrm{T}=2$ tahun & $\mathrm{T}=2$ tahun \\
\hline Sekunder 1 & 0,018 & 171 & 174 & 0,013873464 & 0,00024972 \\
\hline Tersier 1 & 0,0027 & 26 & 26 & 0,013873464 & 0,00003746 \\
\hline Kuarter 1 & 0,0027 & 26 & 26 & 0,013873464 & 0,00003746 \\
\hline Kuarter 2 & 0,0057 & 54 & 55 & 0,013873464 & 0,00007908 \\
\hline Jumlah & 0,0291 & & & & \\
\hline
\end{tabular}

Untuk perhitungan debit rancangan berdasarkan air hujan (Qah) pada ruas saluran terlebih dahulu dilakukan perhitungan terhadap beberapa variabel yaitu koefisien pengaliran, waktu konsentrasi dan Intensitas hujan. Contoh perhitungan untuk ruas saluran untuk $\mathrm{T}=2$ tahun disajikan pada Tabel 5.

Tabel 5. Perhitungan Debit Rencana selama 2 Tahun

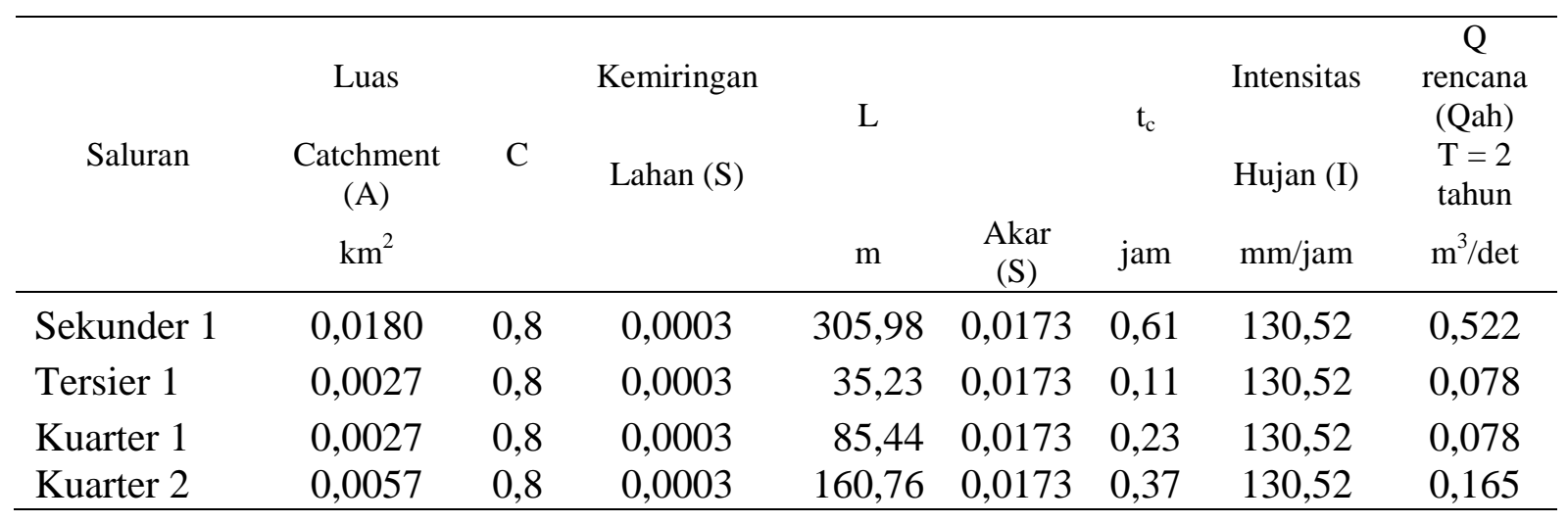

Saluran Sekunder 1 dengan luas penampang saluran $4.95 \mathrm{~m} 2$ dan debit eksisting 3.51 $\mathrm{m} 3 /$ det dan debit yang membebani saluran $0.84 \mathrm{~m} 3 /$ det maka kondisi masih aman tidak terjadi luapan. 
Saluran Tersier 2 dengan luas penampang saluran $1.89 \mathrm{~m} 2$ dan debit eksisting 0.099 dan debit yang membebani saluran0.322 maka kondisi saluran tersebut tidak aman dan terjadi luapan.

Saluran Kuarter 1 dengan luas penampang saluran $0.525 \mathrm{~m} 2$ dan debit eksisting $0.132 \mathrm{~m} 3 /$ det dan debit yang membebani saluran $0.244 \mathrm{~m} 3 /$ det maka kondisi saluran tersebut tidak aman dan terjadi luapan. Saluran Kuarter 2 dengan Luas Penampang Saluran 1.04 m2 dan debit eksisting $0.010 \mathrm{~m} 3 /$ det dan debit yang membebani saluran $0.165 \mathrm{~m} 3 /$ det maka kondisi saluran tersebut tidak aman dan terjadi luapan.

Saluran Sekunder 1 dimensi penampang tidak diubah, karena debit eksisting lebih besar dari debit yang membebani saluran. Saluran Tersier 2 dimensi saluran diubah dari lebar $=0,90 \mathrm{~m}$, kedalaman $=2,10 \mathrm{~m}$ menjadi lebar 1,90 m, kedalaman =2,10 m sehingga dengan dibesarkannya penampang saluran maka debit saluran lebih besar dari debit yang akan diterima.

Saluran Kuarter 1 dimensi saluran diubah dari lebar $=0,35 \mathrm{~m}$, kedalaman $=1,50 \mathrm{~m}$ menjadi lebar 0,60 $\mathrm{m}$, kedalaman $=1,50 \mathrm{~m}$ sehingga dengan dibesarkannya penampang saluran maka debit saluran lebih besar dari debit yang akan diterima. Saluran Kuarter 2 dimensi saluran diubah dari lebar $=0,35 \mathrm{~m}$, kedalaman $=2,98 \mathrm{~m}$ menjadi lebar 2,0 m, kedalaman $=2,98 \mathrm{~m}$ sehingga dengan dibesarkannya penampang saluran maka debit saluran lebih besar dari debit yang akan diterima.

\section{Kesimpulan dan Saran}

\subsection{Kesimpulan.}

Dampak yang terjadi akibat dimensi saluran yang menyempit adalah tidak tertampungnya air buangan warga, apalagi ditambah dengan debit yang berasal dari air hujan, maka akan terjadi luapan. Perkiraan debit yang terjadi selama 2 tahun yang akan datang adalah Saluran Sekunder 1, 0.524 m3/det. Saluran Tersier 1, 0.079 m3/det, Saluran Kuarter 1, 0.079 m3/det. Saluran Kuarter 2, 0.166 m3/det.

Saluran Sekunder 1 dengan Luas Penampang Saluran $4.95 \mathrm{~m} 2$ dan debit eksisting $3.51 \mathrm{~m} 3 /$ det dan debit yang membebani saluran $0.84 \mathrm{~m} 3 /$ det maka kondisi masih aman tidak terjadi luapan. Saluran Tersier 2 dengan Luas Penampang Saluran $1.89 \mathrm{~m} 2$ dan debit eksisting 0.099 dan debit yang membebani saluran0.322 maka kondisi saluran tersebut tidak aman dan terjadi luapan. 
Saluran Kuarter 1 dengan Luas Penampang Saluran 0.525 m2 dan debit eksisting $0.132 \mathrm{~m} 3 /$ det dan debit yang membebani saluran $0.244 \mathrm{~m} 3 /$ det maka kondisi saluran tersebut tidak aman dan terjadi luapan. Saluran Kuarter 2 dengan Luas Penampang Saluran 1.04 m2 dan debit eksisting $0.010 \mathrm{~m} 3 /$ det dan debit yang membebani saluran $0.165 \mathrm{~m} 3 / \mathrm{det}$ maka kondisi saluran tersebut tidak aman dan terjadi luapan.

Pembesaran kapasitas saluran dapat menanggulangi banjir adalah dengan menambah dimensi saluran di saluran-saluran yang terjadi luapan. Saluran Sekunder 1 dimensi penampang tidak diubah, karena debit eksisting lebih besar dari debit yang membebani saluran. Saluran Tersier 2 dimensi saluran diubah dari lebar $=0,90 \mathrm{~m}$, kedalaman $=2,10 \mathrm{~m}$ menjadi lebar 1,90 m, kedalaman $=2,10 \mathrm{~m}$ sehingga dengan dibesarkannya penampang saluran maka debit saluran lebih besar dari debit yang akan diterima. Saluran Kuarter 1 dimensi saluran diubah dari lebar $=0,35 \mathrm{~m}$, kedalaman $=1,50 \mathrm{~m}$ menjadi lebar $0,60 \mathrm{~m}$, kedalaman $=1,50 \mathrm{~m}$ sehingga dengan dibesarkannya penampang saluran maka debit saluran lebih besar dari debit yang akan diterima. Saluran Kuarter 2 dimensi saluran diubah dari lebar $=0,35 \mathrm{~m}$, kedalaman $=2,98 \mathrm{~m}$ menjadi lebar 2,0 m, kedalaman $=2,98 \mathrm{~m}$ sehingga dengan dibesarkannya penampang saluran maka debit saluran lebih besar dari debit yang akan diterima.

\subsection{Saran}

Adapun saran yang dapat penulis sampaikan dalam penyusunan paper berikut dabat dibahas dalam poin - poin berikut :

1. Memperbaiki tata guna lahan, merencanakan sistem drainase yang tepat sesuai dengan daerah tersebut.

2. Meningkatkan peran serta masyarakat dan pemerintah untuk selalu memelihara sistem drainase dengan tidak membuang sampah ke saluran drainase dan membersihkan saluran dari sampah, sedimentasi yang menghambat aliran air dan menurunkan daya tampung sistem drainase

3. Pembangunan-pembangunan yang dilakukan hendaknya mempertimbangkan sitem drainase sehingga daerah resapan air dan saluran air tidak terhambat. 


\section{Daftar Pustaka}

[1] K. Sari, "Management strategy of sustainable urban drainage in Pekanbaru City," IOP Conf. Ser. Earth Environ. Sci., vol. 361, no. 1, 2019.

[2] A. D. Limantara, A. I. Candra, and S. W. Mudjanarko, "MANAJEMEN DATA LALU LINTAS KENDARAAN BERBASIS SISTEM INTERNET CERDAS KADIRI," no. November, pp. 1-2, 2017.

[3] R. D. Putri, D. Priyantoro, L. Prasetyorini, and H. Suprijanto, "Evaluasi Sistem Drainase Daerah Muara Boezem Utara Marokrembangan Surabaya," vol. c.

[4] S. N. Kane, A. Mishra, and A. K. Dutta, "Preface: International Conference on Recent Trends in Physics (ICRTP 2016)," J. Phys. Conf. Ser., vol. 755, no. 1, 2016.

[5] S. Jun, L. Xue, and Y. Jiali, "Evaluation of Drainage Capacity in Old Urban Area of Tongshan County Based on SWMM Model," IOP Conf. Ser. Earth Environ. Sci., vol. 358 , no. 2, 2019.

[6] R. Saputo and S. Suprayogi, "Evaluasi Kapasitas Saluran Drainase Perkotaan ( studi kasus: Daerah Tangkapan Air Klitren, Gondokusuman, Yogyakarta )," J. Chem. Inf. Model., vol. 53, no. 9, pp. 1689-1699, 2013.

[7] R. Tamimi, S. Wahyuni, and E. Hidayah, "Kajian Evaluasi Sistem Drainase Jalan Srikoyo Kecamatan Petrang Kabupaten Jember," Rekayasa Sipil, vol. 10, no. 2, pp. 106-113, 2016.

[8] B. Sulistiono, "Evaluasi Kapasitas Saluran Drainase Desa Sariharjo," J. Eval. Kapasitas Saluran Drainse, vol. 14, no. 1, pp. 47-52, 2016.

[9] E. Supriyani, M. Bisri, and V. Dermawan, "( Studi Kasus Sub Sistem Drainase Magersari Kota Mojokerto ),” vol. 3, pp. 112-121, 2012.

[10] F. Isnaini, Y. Sri Sundari, and H. Purnomo, "Evaluasi Kapasitas Daya Tampung Saluran Drainase Jalan Damanhuri Pada Kota Samarinda," J. Chem. Inf. Model., vol. 53, no. 9, pp. 1689-1699, 2013.

[11] E. Adiputra Winarko, E. Antonio Richard, C. Kusumastuti, and R. Djajadi, "Evaluasi Kapasitas Saluran Drainase Di Kecamatan Pajarakan Kabupaten Probolinggo,” pp. 8592, 2016.

[12] G. Markovic and M. Zelenakova, "Measurement and evaluation of percolation drainage systems capacity in real conditions," IOP Conf. Ser. Earth Environ. Sci., vol. 92, no. 1, 2017. 
[13] A. Sarminingsih, "Drainage System Evaluation as An Effort to Reduce Flood Inundation in Gedebage Area, Bandung - West Java," IOP Conf. Ser. Earth Environ. Sci., vol. 366, no. 1, 2019.

[14] W. Wihaji, R. Achmad, and N. Nadiroh, "Policy evaluation of runoff, erosion and flooding to drainage system in Property Depok City, Indonesia," IOP Conf. Ser. Earth Environ. Sci., vol. 191, no. 1, 2018.

[15] D. I. K. Perdamaian and K. Stabat, "Evaluasi sistem drainaase terhadap genangan di kelurahan perdamaian, kecamatan stabat kabupaten langkat."

[16] R. Laset Saputra, M. Fauzi, and B. Sujatmoko, "Evaluasi Masalah Drainase Jalan Jendral Sudriman Kota Duri Kecamatan Mandau Kabupaten Bengkalis,” vol. 1, no. 2, pp. 1-8, 2014.

[17] H. Wahyudiono, "PERENCANAAN PONDASI BORE PILE PADA PROYEK JEMBATAN NGUJANG II KAB.TULUNGAGUNG,” UKaRsT, vol. 2, no. 1, 2018.

[18] B. Andana, D. Arisanty, S. Adyatma, and I. Pendahuluan, "Evaluasi daya tampung sistem drainase di kecamatan banjarmasin selatan," JPG (Jurnal Pendidik. Geogr., vol. 3, no. 4, pp. 1-13, 2016.

[19] S. Sosrodarsono and K. Takeda, Hidrologi Untuk Pengairan. 1973.

[20] H. Suryaman, "Evaluasi Sistem Drainase Kecamatan Ponorogo Kabupaten Ponorogo," vol. 02, no. 02, pp. 0-07, 2013.

[21] A. Rahmawati, A. Damayanti, and E. S. Soedjono, "Evaluasi Sistem Drainase Terhadap Penanggulangan Genangan di Kota Sidoarjo," Atpw, no. October, pp. 1-8, 2015.

[22] Soemarto, "Hidrologi Teknik Edisi Ke - 2," Erlangga : Jakarta, 1999.

[23] A. I. Candra, E. Gardjito, Y. Cahyo, and G. A. Prasetyo, "Pemanfaatan Limbah Puntung Rokok Filter Sebagai Bahan Campuran Beton Ringan Berpori,” UKaRsT, vol. 3, no. 1, p. 82, 2019.

[24] Suroso, A. Suharyanto, M. Ruslin Anwar, Pudyono, and D. H. Wicaksono, "Evaluasi dan perencanaan ulang saluran drainase pada kawasan perumahan sawojajar kecamatan kedungkandang kota malang,” vol. 8, no. 3, pp. 207-213, 2014. 